\title{
Association between serum uric acid and some cardiovascular risk factors in a Chinese population
}

\author{
J. Woo, R. Swaminathan ${ }^{3}$, C. Cockram, E. Lau ${ }^{1}$ and A. Chan ${ }^{2}$
}

Departments of Medicine, ${ }^{1}$ Community and Family Medicine, and ${ }^{2}$ Chemical Pathology, The Chinese University of Hong Kong, Hong Kong; and ${ }^{3}$ Department of Clinical Biochemistry, Guy's Hospital Medical School, London, UK

\begin{abstract}
Summary: The association between serum uric acid concentration and some cardiovascular risk factors was examined in a working Hong Kong Chinese population (mean age 38 years), consisting of 910 men and 603 women. There was no significant age-related rise in serum uric acid concentration. Positive associations were found between serum uric acid concentration and body mass index, waist hip ratio, systolic and diastolic blood pressure, urea, creatinine, protein, glucose (fasting and 2 hours after $75 \mathrm{~g}$ oral glucose load), 2 hour insulin, triglycerides, and apolipoprotein B in men. Similar, but fewer, associations were seen in women, with the addition of a positive association with age. In both sexes, serum uric acid was negatively associated with high-density lipoprotein cholesterol. These findings complement the well-known clinical association between gout and cardiovascular and metabolic diseases, such as hypertension, hyperlipidaemia and diabetes mellitus, and suggest that serum uric acid may be a marker for the presence of an adverse cardiovascular risk factor profile.
\end{abstract}

\section{Introduction}

The association between gout or hyperuricaemia with hypertension and metabolic disorders, such as diabetes mellitus and hyperlipidaemia, is well documented in Caucasian populations. ${ }^{1-4}$ However, there appear to be racial differences in these associations. $^{5}$ There is little information on the relationship between serum uric acid and cardiovascular risk factors in Chinese subjects. We examined this relationship using results from a community survey of an adult working Chinese population in Hong Kong.

\section{Subjects and methods}

In 1990, a survey was carried out among a Hong Kong Chinese working population to determine the prevalence of diabetes mellitus and the lipid profile. All employees of a public utility company were persuaded to join. As this company had relatively fewer women, all female employees of a general district hospital (excluding medical and paramedical staff) were also persuaded to join in the survey. Response rates for the utility company were $72 \%$ and $63 \%$ for men and women, and $50 \%$

Correspondence: Jean Woo, M.D., F.R.C.P., Department of Medicine, Prince of Wales Hospital, Shatin, NT, Hong Kong.

Accepted: 24 January 1994 among hospital employees. Blood pressure was measured in the sitting position using a mercury sphygmomanometer. A mean of two readings was used. Height was measured with a tape with the subject standing upright against the wall. Weight was measured to the nearest $0.1 \mathrm{~kg}$, with the subject in light clothing without shoes, using a bathroom scale. The body mass index (BMI) was calculated as the weight $(\mathrm{kg})$ divided by the square of the height $(\mathrm{m})$. Waist circumference $(\mathrm{cm})$ was taken as the minimum circumference between the umbilicus and xiphoid process, to the nearest $0.5 \mathrm{~cm}$. The hip circumference was the maximum circumference around the buttocks posteriorly and the symphysis publis anteriorly, to the nearest $0.5 \mathrm{~cm}$. The mean of two measurements was recorded, and the waist hip ratio (WHR) was calculated by dividing the waist by the hip circumference. The parameter was used as an index of central obesity.

Twenty millilitres of blood were taken from the antecubital vein after a 12-hour fast, for measurement of complete blood picture: urea, creatinine, uric acid, total protein, albumin, calcium, glucose, glycosylated haemoglobin (A1C), fructosamine, cholesterol (TC), triglycerides (TG), high-density lipoprotein cholesterol (HDL), low density lipoprotein cholesterol (LDL), apolipoprotein AI (apo A-I) and apolipoprotein B (Apo B). A total of $75 \mathrm{~g}$ of glucose monohydrate in $150 \mathrm{ml}$ of water was given to each subject and was consumed within 5 minutes. One millilitre of venous blood was drawn 
2 hours after glucose loading for estimation of plasma glucose. All specimens were transported in ice to the laboratory within 4 hours of sampling.

Plasma urea, creatinine, uric acid, total protein, albumin, and calcium were measured in an automated multichannel analyser by standard methods (American Monitor Parallel, IN, USA). Plasma calcium $(\mathrm{Ca})$ concentration was corrected for variation in plasma albumin concentration by the following formula: ${ }^{6}$

\section{Albumin-adjusted $\mathrm{Ca}=$ measured $\mathrm{Ca}+0.025$}

(40-albumin concentration).

TC and TG were assayed enzymatically with commercial reagents (Baker Instruments Corporation, Allentown, PA, USA). HDL was determined after fractional precipitation with dextran sulphate- $\mathrm{MgCl}_{2}{ }^{7} \mathrm{LDL}$ was calculated using the Friedewald's formula. ${ }^{8}$ Apolipoproteins AI and B were assayed by rate immunonephelometry (Array analyzer, Beckman Instruments, Inc., Bera, CA, USA). Interassay coefficients of variation were: TC, $1.9 \%$ at $6.4 \mathrm{mmol} / \mathrm{l}$; TC, $2.6 \%$ at $1.9 \mathrm{mmol} / \mathrm{l}$; HDL, $5.4 \%$ at $0.86 \mathrm{mmol} / \mathrm{l}$; Apo AI $2.2 \%$ at $136 \mathrm{mg} / \mathrm{dl}$; and Apo B, $2.8 \%$ at $85 \mathrm{mg} / \mathrm{dl}$.

Plasma glucose was assayed with the Trinder reagent (Diagnostic Chemicals Ltd, Charlotte Town, Canada) on a Cobas Mira analyser (Hoffmann-La Roche \& Co., Basle, Switzerland). AlC was measured by ion exchange high performance liquid chromatography, using a Bio-Rad DIAMAT Analyzer (Bio-Rad Laboratories, California, USA). Interassay coefficients of variation for glucose, fructosamine, and $\mathrm{AlC}$ were $2.0 \%$ at $6.6 \mathrm{mmol} / 1,20 \%$ at $1.51 \mathrm{mmol} / 1$ and $<3.1 \%$ at values below $8.5 \%$, respectively. Insulin assay was performed using a radioimmunoassay kit (Pharmacia Insulin RIA 100, Pharmacia Diagnostics AB, Uppsala, Sweden). The lower limit of detection was $<0.01 \mathrm{mmol} / \mathrm{l}$. Cross-reactivity with Cpeptide was $<0.18 \%$ (by weight). The coefficient of variation between kits was $5 \%$.

As microalbuminuria has been considered a cardiovascular risk factor, ${ }^{9}$ we also collected a morning fasting urine specimen for detection of microalbuminuria. This was estimated as the albumin:creatinine ratio $(\mathrm{Alb} / \mathrm{Cr})$. Urinary albumin was determined immunoturbidimetrically with use of a commercial antibody (Dako Patts a/s, Glostrup, Denmark) and a Cobas Bio Centrifugal analyser, ${ }^{10}$ and creatinine concentration was measured by the Jaffe reaction on an Astra 8 autoanalyser (Beckman Instruments, Inc., Bera, CA, USA).

Results were analysed using the Statistical Package for Social Sciences (Vers 3.0) for IBM PC. One-way analysis of variance was used to detect significant differences in mean values according to age groups. Pearson's correlation coefficient was used to detect association between variables. Associations with these variables were also examined by mean levels of each variable by tertiles of uric acid, using the ANOVA to test for statistical significance. Multiple linear regression using the stepwise procedure was used to assess independent contributions of different variables showing significant associations with serum uric acid concentation.

\section{Results}

Table I shows that mean \pm s.d. values of serum uric acid and other variables according to different age groups. Results are given for men and women separately as mean serum uric acid concentration is significantly lower in women. No age-related change in serum uric acid was observed in men but mean values increased with age in women. However, there was an increase with age in values of variables known to increase cardiovascular risk: BMI, WHR, blood pressure, glucose, insulin, $A_{1} C$, cholesterol (total, LDL and VLDL fractions), triglycerides, and apolipoprotein B. In men, serum uric acid correlated positively with most of these factors: BMI, WHR, systolic blood pressure (SBP), diastolic blood pressure (DBP), fasting and 2 hour glucose, 2 hour insulin, triglycerides and apolipoprotein B (Table II). A negative correlation with HDL was present. As expected, there was a positive correlation with urea and creatinine. Similar results were seen with women, except that there were fewer significant associations and uric acid correlated positively with age. When adjusted for age, essentially the same results were obtained in men; however, only the negative association with HDL remained significant in women. After adjustment for age and BMI, the only significant variables were creatinine, protein, albumin-adjusted calcium, HDL in men and HDL in women.

When all the variables showing significant association with serum uric acid were put into a stepwise multiple regression model, six variables were shown to be independently associated with serum uric acid, accounting for $12 \%$ and $23 \%$ of the variability in men and women, respectively. Both BMI and creatinine accounted for the major part of the variability in men and women. WHR, urea, protein and triglycerides accounted for a small percentage of the variability in men, while triglycerides, protein, apolipoprotein $B$ and $A_{1} C$ accounted for the rest of the variability in women. Associations with the variables shown in Table III are also presented by mean levels according to tertiles of uric acid (Table IV). 
Table II Correlation coefficients (Pearson's) between uric acid and other variables

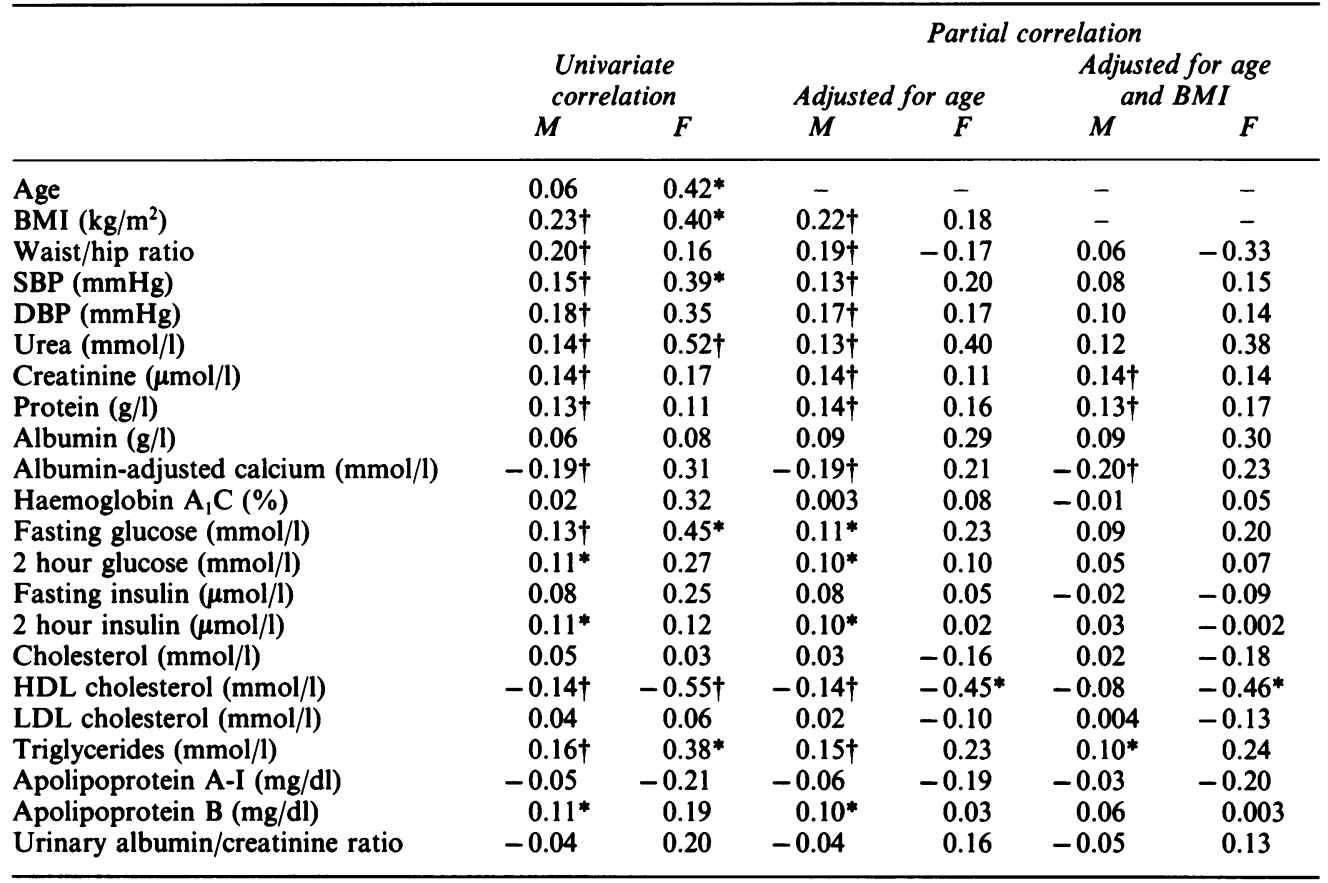

$* P$ value $\leqslant 0.01 ; \dagger P$ value $\leqslant 0.001$

Table III Stepwise multiple regression analysis. Dependent variable: uric acid $(\mathrm{mmol} / \mathrm{l})$

\begin{tabular}{|c|c|c|c|c|}
\hline Independent variable & $\boldsymbol{B}$ & $S E B$ & $\% \mathrm{R}^{2}$ & $\mathbf{F}$ \\
\hline \multicolumn{5}{|l|}{ Men } \\
\hline BMI (per kg/m²) & 0.004 & 0.001 & 5.1 & $47.2^{*}$ \\
\hline Creatinine (per $\mu \mathrm{mol} / \mathrm{l})$ & 0.001 & 0.0003 & 2.7 & $37.4^{*}$ \\
\hline WHR (per cm/cm) & 0.18 & 0.06 & 1.3 & $29.4^{*}$ \\
\hline Urea (per mmol/l) & 0.007 & 0.003 & 1.0 & $24.7^{*}$ \\
\hline Protein (per $\mathrm{g} / \mathrm{l}$ ) & 0.002 & 0.0007 & 0.97 & $21.9^{*}$ \\
\hline Triglyceride (per mmol/l) & 0.009 & 0.004 & 0.61 & $19.4^{*}$ \\
\hline Constant & -0.16 & 0.07 & & \\
\hline Total & & & 11.7 & $19.4^{*}$ \\
\hline \multicolumn{5}{|l|}{ Women } \\
\hline Creatinine (per $\mu \mathrm{mol} / \mathrm{l}$ ) & 0.001 & 0.0002 & 12.2 & $77.1^{*}$ \\
\hline BMI $\left(\right.$ per $\left.\mathrm{kg} / \mathrm{m}^{2}\right)$ & 0.004 & 0.0008 & 5.8 & $61.6^{*}$ \\
\hline Triglycerides (per mmol/l) & 0.012 & 0.004 & 2.4 & $47.8^{*}$ \\
\hline Apolipoprotein B (per mg/dl) & 0.0003 & 0.0001 & 1.0 & $37.9 *$ \\
\hline Protein (per $g / l$ ) & 0.002 & 0.0007 & 0.7 & $31.5^{*}$ \\
\hline$A_{1} C($ per one $\%)$ & 0.007 & 0.003 & 0.7 & $27.3^{*}$ \\
\hline Constant & -0.02 & 0.06 & & \\
\hline Total & & & 0.23 & $27.3^{*}$ \\
\hline
\end{tabular}

$B=$ regression coefficient; $S E B=$ standard error of regression coefficient; $R=$ variance; $F=F$ value to indicate significance of analysis of variance. $* P \leqslant 0.001$ 
Table IV The mean value and standard deviation of uric acid by tertiles of other variables

\begin{tabular}{|c|c|c|c|c|c|c|}
\hline & lst & $\begin{array}{l}\text { Men } \\
\text { Tertiles } \\
2 n d\end{array}$ & $3 r d$ & 1st & $\begin{array}{c}\text { Women } \\
\text { Tertiles } \\
2 \text { nd }\end{array}$ & $3 r d$ \\
\hline BMI $\left(\mathrm{kg} / \mathrm{m}^{2}\right)$ & $0.37(0.11)$ & $0.39(0.09)$ & $0.41(0.07) \ddagger$ & $0.29(0.07)$ & $0.30(0.06)$ & $0.33(0.06) t$ \\
\hline Creatinine $(\mu \mathrm{mol} / \mathrm{l})$ & $0.38(0.06)$ & $0.38(0.10)$ & $0.40(0.08) \dagger$ & $0.30(0.06)$ & $0.32(0.06)$ & $0.53(0.14) \ddagger$ \\
\hline Waist/hip ratio & $0.35(0.05)$ & $0.38(0.06)$ & $0.41(0.11) \ddagger$ & $0.30(0.06)$ & $0.32(0.07)$ & $0.34(0.06) \ddagger$ \\
\hline Urea (mmol/l) & $0.37(0.12)$ & $0.39(0.07)$ & $0.40(0.09) \ddagger$ & $0.30(0.05)$ & $0.31(0.08)$ & $0.33(0.08) \ddagger$ \\
\hline Protein $(\mathrm{g} / \mathrm{l})$ & $0.38(0.09)$ & $0.39(0.06)$ & $0.41(0.11) \ddagger$ & $0.30(0.07)$ & $0.30(0.07)$ & $0.32(0.07) \dagger$ \\
\hline Triglyceride (mmol/l) & $0.37(0.05)$ & $0.39(0.12)$ & $0.41(0.07) \ddagger$ & $0.29(0.07)$ & $0.31(0.06)$ & $0.34(0.06) \ddagger$ \\
\hline Apolipoprotein-B (mg/dl) & $0.38(0.11)$ & $0.39(0.07)$ & $0.40(0.09)^{*}$ & $0.29(0.07)$ & $0.31(0.06)$ & $0.33(0.07) \ddagger$ \\
\hline Haemoglobin $\mathrm{A}_{1} \mathrm{C}(\%)$ & $0.39(0.06)$ & $0.39(0.12)$ & $0.39(0.07)$ & $0.30(0.05)$ & $0.31(0.09)$ & $0.34(0.08) \ddagger$ \\
\hline
\end{tabular}

${ }^{*} P$ value $<0.05$ from ANOVA test; $\nmid P$ value $<0.01$ from ANOVA test; $\ddagger P$ value $<0.001$ from ANOVA test.

\section{Discussion}

In our Chinese population, cardiovascular disease is the second commonest cause of mortality after neoplasm. ${ }^{11}$ The prevalence of hypertension is $17 \%$ for men and $5 \%$ for women, ${ }^{12}$ while that for diabetes mellitus is $4.5 \%,{ }^{13}$ rising to over $10 \%$ in the population aged 60 years and above. ${ }^{14}$ Gout is not a rare disease in our population, although there are no studies documenting its prevalence in Hong Kong Chinese. Although genetic factors may contribute to hyperuricaemia and gout, ${ }^{15}$ it is the environmental factors which provide modifiable means of prevention. The positive association of uric acid concentration with many of the cardiovascular risk factors suggests that uric acid concentration may also be affected by cardiovascular risk factor modification.

As in other studies, ${ }^{5}$ uric acid concentration is lower in women, possibly due to the effect of oestrogens. ${ }^{2,16}$ Although serum uric acid rises with age in childhood, a plateau appears to be reached by about 18 years of age. ${ }^{5}$ Therefore it is not surprising to find an absence of age-related rise in our working population, which has a mean age of 38 years. If our study included the elderly as well, one might well see a rise in serum uric acid concentration with age in parallel with the rising urea and creatinine as a result of age-related decline in renal function. Parallel to the lower serum uric acid concentration in women, the cardiovascular risk factor profile is also more favourable in women, who have lower cholesterol, triglycerides, apolipoprotein B, and higher HDL cholesterol and apoloprotein A-I. However, mean values of these variables rose significantly with age, unlike serum uric acid.

The positive association between serum uric acid, BMI, WHR, systolic and diastolic blood pressure, cholesterol, LDL cholesterol, triglycerides, apolipoprotein B, glucose, insulin, and the negative association with HDL cholesterol are similar to the findings in a Caucasian population. The magnitude of the correlation coefficients is also similar. The basis for these associations is unclear. Serum uric acid concentration is influenced by the rate of production by purine metabolism on the one hand, and the rate of renal tubular secretion, on the other. Since purine nucleotides are involved in the intermediary metabolism of lipids and carbohydrates, and renal tubular secretion reflects renal function, it is not surprising that the two factors accounting for a large percentage variance in serum uric acid concentration are body mass index (which is positively associated with adverse lipid and carbohydrate profile), and creatinine, an index of renal function. This association suggests that serum uric acid may be considered a marker for the presence of an adverse cardiovascular risk factor profile and that improvement of this profile by whatever means may also influence serum uric acid concentration.

\section{References}

1. Breckenridge, A. Hypertension and hyperuricaemia. Lancet 1966, 1: 15 .

2. Mikkelsen, W.M. The possible association of hyperuricaemia and/or gout with diabetes. Arthritis Rheum 1965, 8: 853-859.

3. Berkowitze, D. Blood lipid and uric acid interrelationships. JAMA 1964, 190: 856.

4. Klein, R., Klein, B.E., Cornoni, J.C. et al. Serum uric acid: its relationship to coronary heart disease risk factors and cardiovascular disease, Evans county, Georgia. Arch Intern Med 1973, 132: 401-410.

5. Agamah, E.S., Srinivasan, S.R., Webber, L.S. \& Berenson G.S. Serum uric acid and its relation to cardiovascular disease risk factors in children and young adults from a biracia community: The Bogalusa Heart Study. J Lab Clin Med 1991, 118: $241-249$.

6. Payne, R.B., Little, A.J., Williams, R.B. \& Milner, J.R Interpretation of serum calcium in patients with abnormal protein. $\mathrm{Br}$ Med J 1973, iv: 643-666. 
7. Talameh, Y., Wei, R. \& Naito, H. Measurement of total HDL, HDL2 and HDL3 by dextran sulphate- $\mathrm{MgCl}_{2}$ precipitation technique in human serum. Clin Chim Acta 1986, 158: 33-41.

8. Friedewald, W.T., Levy, R.I. \& Frederickson, D.S. Estimation of plasma low density lipoprotein cholesterol concentration without the use of the preparative ultracentrifuge. Clin Chem 1972, 18: 499-512.

9. Haffiner, S.M., Stern, M.P., Gruber, M.K.K., Hazuda, H.P., Mitchell, B.D. \& Patterson, J.K. Microalbuminuria. Potential marker for increased cardiovascualr risk factors in nondiabetic subjects? Arteriosclerosis 1990, 10: 727-731.

10. Cheung, C.K. \& Swaminathan, R. Rapid, economical immunoturbidimetric method for microalbuminuria. Clin Chem 1987, 33: 204-205.

11. Statistical Appendix. In: Tam, H.C. (ed.) Medical Directory of Hong Kong, 4th edn. Federation of Medical Society of Hong Kong, 1989, p. 439.

12. Woo, J., Lau, E., Chan, A., Cockram, C. \& Swaminathan, R. Blood pressure and urinary cations in a Chinese population. $J$ Human Hypertens 1992, 6: 299-304.
13. Cockram, C.S., Woo, J., Lau, E. et al. The prevalence of diabetes mellitus and impaired glucose tolerance among Hong Kong Chinese adults of working age. Diabetes Res Clin Prac 1993, 21: 67-73.

14. Woo, J., Swaminathan, R., Cockram, C., Pang, C.P., Mak, Y.T., Au, S.Y. \& Vallance-Owen, J. The prevalence of diabetes mellitus and an assessment of methods of detection among a community of elderly Chinese in Hong Kong. Diabetologia 1987, 30: 863-868.

15. Finn, R., Jones, P.O., Tweedie, M.C.K., Hall, S.M., Dinsdale, O.F. \& Bowidillon, R.E. Frequency distribution curve of uric acid in the general population. Lancet 1966, 2: 185-187.

16. Nicholls, A., Snaith, M.L. \& Scott, J.T. Effect of oestrogen therapy on plasma and urinary levels of uric acid. $\mathrm{Br}$ Med $J$ 1973, 1: 449. 